\title{
'Teaching Fixturing for Manufacturing Processes within the Learning Factory between Worcester Polytechnic Institute and Pratt \& Whitney
}

\author{
Fredric M. Gold, John J. Bausch, III \\ Worcester Polytechnic Institute
}

\begin{abstract}
:
Engineering education is undergoing serious scrutiny by industry and academia due to perceived gaps in undergraduate education. Project based learning, at the undergraduate level, is an important facet of addressing this perception by acquainting students with new processes and tools. It requires students to understand not only the fundamentals of engineering science but also to be able to apply what they know to "real" problems and issues. Most undergraduates attend the university for four or five years, and it is not possible to teach the students everything that they might need to know in that time period. The fundamentals of tool and fixture design is an area that has not been emphasized in undergraduate education. Fixturing is one of the least understood and yet most fundamental of manufacturing processes. Undergraduate and graduate students from Worcester Polytechnic Institute(WPI) have been on site at Pratt and Whitney Aircraft (PWA) in North Haven, CT., working on some of their fixturing issues within the Learning Factory. This paper examines the importance of project based learning, how WPI and PWA have incorporated it into the Learning Factory and the difficulties of teaching fixturing and tool design.
\end{abstract}

\section{Changing Engineering Education}

$\mathrm{R}$ has been noted that the technology used by some industries has surpassed that of the academic environment (Sisson 1996), This implies that students who then go to work for these companies are not adequately trained to use the tools that are available. Engineers coming out of school have been trained for four to five years to be able to perform a job, if they then need further training before they can become an effective member of the company team, companies may see this as a lack of education.

As technology continues to change, particularly with the advantages of better computers and tools, industry and academia must change as well. The companies and universities that do not change will be left behind by their competitors that do. Pratt \& Whitney approached WPI to create the Learning Factory in order to improve undergraduate education at a fundamental level, creating a trickle down effect, where Pratt and Whitney will be improved fundamentally at several levels, The first is by sharing strengths of both industry and academia and by relying on the others' strengths to overcome individual limitations, The second is by having students work on projects at Pratt and Whitney to provide new perspectives to challenging issues. This also introduces students to a different culture while they are undergraduates. This creates the third level, which is the company hiring students who have worked on their problems, been exposed to their culture and are familiar with their needs and requirements before they ever actually go to work there, making them a more productive employee in a much shorter period of time. 
As part of the REALIZATION Consortium (discussed later) a Gaps Analysis was initiated to determine where the perceived gaps in undergraduate education are and where academia should focus their attentions: The areas shown, in table 1, are most of the highest gaps identified and point out the need for project centers such as the Learning Factory, These areas that students were felt to be deficient in, are the very ones stressed in the project groups. To summarize the gaps analysis, 8 companies were queried and the results tabulated. The average response in the table is based on the eight companies surveyed and is based on a scale of O (no importance) to 10 (most important) (Sisson 1996).

\begin{tabular}{|c|l|c|}
\hline & Gap Area & Average Response \\
\hline 1) & CAD Training & 6.36 \\
\hline 2) & Written Reports and Presentations & 8.04 \\
\hline 3$)$ & Teamwork & 7.86 \\
\hline 4$)$ & Problem Solving & 8.10 \\
\hline 5) & Design for Manufacture & 8.08 \\
\hline 6$)$ & Systems Approach to Design & 8.04 \\
\hline
\end{tabular}

Table 1

\section{LEARNING FACTORY}

The Learning Factory is a new program between WPI and Pratt \& Whitney Aircraft (PWA) where students work on-site on a specific project for seven weeks. The project is identified by both the engineers and managers of Pratt and Whitney as well as the advisors and coordinators from WPI.

Pratt \& Whitney Aircraft (PWA) is a well-known producer of aircraft engines. The North Haven plant of PWA is primarily dedicated to the production of turbine blades and vanes for the aircraft engines. Recently, PWA went through a major restructuring of their production lines, processes and personnel. They approached WPI with a vision and a willingness to open their facilities to create a Learning Factory. They proposed that fundamental long term changes and improvements within engineering education will allow them to achieve their future goals and the changes that will keep them ahead of their competitors (Bausch 1996).

The students at WPI must complete three projects as undergraduates, a Sufficiency, an Interactive Qualifying Project (IQP) and a Major Qualifying Project (MQP). The MQP is typically done over the senior year and is an engineering research project within the students' major field of study, the undergraduate projects done within the Learning Factory have all been MQP's.

The school year at WPI is divided into two semesters each divided into two terms, The students take three courses per quarter or term. A typical MQP counts for three courses and would be completed in A, $\mathrm{B}$ and $\mathrm{C}$ terms. The Learning Factory has students on site at PWA for one term. The term before they are on site the students are required to investigate the project that they will be working on and to write a pre-project proposal, including what they will be doing, an initial time line and who their main contacts are. Most of this information is obtained by talking to the employees that they will be working with, students who have worked on some aspect of their project before and discussing their project with their advisor and the on-site coordinator. The term when the students come back to WPI, they are required to do a write-up of their project and make a final presentation to both WPI and PWA.

At the same time as the undergraduate projects, there are two graduate level projects ongoing, one Master's student and one Ph.D. candidate. One graduate student also functions as the site-coordinator for 
the undergraduate projects. His responsibilities include initial project operation, project documentation, communication, direction in company procedures and the project apartment.

-Sinee PWA is almost 2 hours commute to WPI a project apartment has been set-up for the students to use while they are on-site, the apartment is capable of sleeping 5 students per term. Preventing the students' residence from costing them anymore than if they were on campus.

The Learning Factory is different from a typical cooperative education position in that the level of commitment is much higher by both the university and the company. Faculty time and resources as well as company time and resources are available to be drawn upon. A shared risk and responsibility for the projects was felt to help insure the commitment of all parties involved. One of the main difficulties is the requirement to maintain an academic standard for the students. For co-op students, the school has very little say or responsibility into what they do or how they do it. For project groups, the school must maintain the academic standards that the projects at WPI achieve, since the projects count as the students senior project (Bausch 1996).

The Learning Factory forces the company, students and faculty to look forward to the future, to push the technology that the company is using, It is also to help better prepare the students to go out to work into an industrial environment, to give them a better perspective on what's currently being done and to offer the company a chance to expand new ideas and new technologies.

Another facet of the Learning Factory is the cultural exchange that inevitably happens. The students who have been in an academic environment are suddenly thrust into a new arena. The company has its own language, its own schedule, its own reasons that may vary significantly from the university. Similarly, the university has its own language and culture that the company is not familiar with. The students must then learn the culture of the company and teach that of the university, addressing both industrial and academic strengths and limitations. The students must confront some of these and overcome them in order to effectively work on their projects. As the Learning Factory develops a new culture should develop that is a hybrid of the two, easing the way for future groups,

To date there have been some "growing pains" associated with the factory that have resulted from differences in time and scheduling. The school year is divided into two semesters, divided into two terms as well as breaks and the summer. The corporate year is fiscal and is governed by projects, proposals and deadlines for customers. Ensuring continuity of student groups and topics has become a primary concern. Again, the students, employees and faculty are partaking of separate cultures and need to be aware of the cultural differences and avoiding the miscommunication that can develop.

\section{Project Based Learning}

According to Acuna et.al. there has been a resurgence of interest into project based learning, both from a practical side and a theoretical side, "As students struggle to solve design problems together, they are forced to negotiate shared meanings of their problem solving experience while using common mediational tools.' (Acuna 1996). Every engineer, except perhaps those that own their own company, work with other engineers on projects during their professional career. It follows then that students should learn how to work effectively in teams before they ever start their professional career. The dynamics of working in a project are much different from working alone. A recent graduate will no longer be able to work on their assignment and turn it in. Industry requires cooperation among their employees to remain competitive. In addition, effective communication is extremely important, Employees who can not express themselves effectively or do not understand someone else, can lead to inefficiencies that may cause wasted time and 
eñergy, repeating work and eventually lack of profits. Because every engineer will be asked to perform well in a team environment, the student should learn to be an effective member of a team while still an untergraduate.

The steps to implementing product realization projects are: problem finding, problem stating, option finding, deciding, taking action, and evaluating results (Acuna 1996). Worthwhile projects need to meet academic and industrial standards. Simple number crunching is not acceptable. Students must be given challenges that will force them to grow into their project but not be overwhelmed by the difficulty or scope of the project. Projects that have direct consequence onto "real" work are much better. The employees must see the students as assets into the work they are doing and not extraneous personnel working on a small insignificant project that could be done later. Therefor, projects need to be identified and agreed upon by both the academic and industrial contacts for the project.

Again, the students need to be given challenging projects that "need" to be done. If they are treated as entry level engineers, rather than students, and given responsibility and ownership of their projects the outcome will be much better. Additionally, support from internal personnel is crucial. Employees of the company must be willing to donate some of their time and energy to the project, either by directly helping the stủdents or at least pointing them in the right directions.

\section{Product REALIZATION}

The Product REALIZATION Consortium is a nationally funded project supported by the National Science Foundation Cooperative Agreement DMI-94 13089 under the interagency Technology Reinvestment Project (TRP). "The mission of the Consortium is to launch a systematic reform of undergraduate engineering education and faculty culture in the USA."(Sisson 1994). The need for the reform is based on a number of facts including: manufacturing is critical to all engineering, design and manufacturing are highly interdependent and technological sophistication in some industries has surpassed that of the university in design and manufacturing. The REALIZATION consortium consists of five schools, WPI, Cornell, NCA\&T, Tuskegee and MIT, and the Society of Manufacturing Engineers. There are five main tasks for the consortium, two of which are relevant here, the development of the Design Studio of the Future and Product Realization Projects (Sisson 1994).

Maintaining communication between the students and the faculty is of paramount importance. The use of the design studio to relieve the difficulties associated with doing a short term project becomes essential. The telecommunication and audio visual tools provide an effective means for discussions and meetings without requiring extensive travel by the faculty or the student group.

The Design Studio is a part of the REALIZATION Consortium and is an open studio environment to do collaborative work and design. It supplies clusters of high performance 3-d graphics workstations, audio/visual telecommunication networking (computer-based) as well as software for simulation, data base use, and multimedia presentations. There exists design studios at the institutions of the REALIZATION consortium to be used to expedite communication and collaboration between institutions and industry, interconnected for visual and audio communications and data sharing (Bausch 1995).

Three key words for the use of the design studio are interaction, integration and communication. The design studio is to facilitate interaction between groups of students, particularly those at geographically distributed locations. It will integrate the students to work as a team as well as integrating various aspects of engineering and science into a cohesive project, The main method for doing this is through communication. Without quality communication the interaction and integration are impossible. Often 
they are difflcult when alt members of a team are together and not a mile, ten miles or a thousand miles away.

The task of the Product Realization Projects is to develop a series of industrially identified customerdriven projects that will culminate in a cross-consortium, multi-institutional project in the senior year. The project will cover identification of a customer need to final product realization, including design, manufacturing, teamwork, as well as the broader management and social issues that arise. The idea is to cross pollinate between academia and industry to create a win-win situation. It is the hope of the Learning Factory that everyone wins, students, professors, employees, and the company itself (Sisson 1994).

\section{Fundamentals of Fixture Design}

Fixturing is one of the least understood and yet most fundamental of manufacturing processes. Where a part is fixtured, what process it is undergoing, and the part requirements significantly change the design of the fixture. The more precise and accurate the final dimensions of the part, the more precision and accuracy required of the fixture. Engineers design the part and then give the drawings to manufacturing. The tool designers and machinists must determine how to hold the part for the required operations. This is often a heuristic approach, with fixture design being more of an art than a science. However, since it is so fundamental, students should be aware of it from the onset. But, as is often the case, the best way to learn is by doing and by watching someone. Educating new tool makers and tool designers is typically done in a form of apprenticeship with the new employees working with experienced employees.

Fixtures are designed to hold, locate and support the part during a machining operation. Other considerations for fixture design for specific parts and processes are cost, production capabilities, production processing and tool life. Quality, rate and accuracy need to be weighed against increased costs for fixture design (Hoffman 1991).

The process that is being used can also significantly affect the fixture design, For instance a fixture for a part that is to be laser machined does not have the same force requirements as a fixture for a part to be milled. Part handling also becomes important in fixture design. The optimum is to handle the part only once. In other words the part is not removed from a fixture until it is done. This prevents errors in switching fixtures or damaging the part in transit (Hoffman 1991).

Companies that make a part and make it well understand the particular fixturing requirements for their part or their family of parts. There may be years of experience within the company. A new employee would have to learn from the experience available at the company to be able to address their particular concerns. These concerns will change from company to company as well as part to part. Additionally, with all of the processes available to machine parts, it would be impossible to introduce students to an indepth study of them all. It becomes a question of time and necessity to academics, Can this material be taught in the allotted time, four years for an undergraduate education, while continuing to provide the necessary background in the other core areas? However, fixturing is so basic to manufacturing that it begs the question, how can we not teach it? Every part that is made needs to be fixtured at some point. The type and requirements of the fixture will change drastically, but the part will be fixtured.

Primarily the main trends in fixture design research are towards automation, increased productivity and computer integration. Expert systems, screw theory, precision machine design, computer integrated manufacturing, computer aided design and more may be used as part of fixture design. Other main areas of fixturing include: flexible tooling, non-permanent general purpose jigs and fixtures, modular fixturing systems (erector sets), fixturing which is suitable for a number of part families and a number of production 
operations, reconfigurable fixturing, automated fixturing design (reconfiguration planning), layout planning, set-up planning, assembly planning and complete fixturing system automation (Bausch 1995).

-The problem then becomes what should be taught and how should it be taught. There are certain fundamentals that should be addressed, particularly fundamentals of locating the parts and machining process capabilities. Undergraduates should have an appreciation of what will be necessary to make a part as they are designing it. The classroom is probably not the best location to teach fixturing. This is where the project opportunities, such as the Learning Factory, play an important role. The students get a chance to see and learn the intricacies of fixture design while being able to draw onto the experience of the employees of the company.

\section{Conclusions}

The Learning Factory between WPI and PWA is a relatively new program, just completing its first year, that tries to blend the advantages of project based learning with teaching the basics of fixturing to undergraduate students. Tooling and fixturing is a fundamentally important area. It is an integral part of the entire manufacturing spectrum that has been overlooked by academics on the whole. It applies many of the other fundamental engineering core areas, incorporating many fields and subjects into one area, Yet, it is a difficult subject to teach in the classroom environment. Project Based Learning is becoming an essential aspect of engineering education, It offers the students a means to learn what many companies have recognized as required skills for success in the workplace. There is great potential for impact by the Learning Factory on how universities address fixturing and apply project based learning to undergraduate education.

\section{References}

(Acuna 1996) Acuna, N.M,, Sisson, Jr., RD., Gold, F.M. "Theoretical Foundations for Design in Project Based Learning Within the Project REALIZATION Consortium”, 1996 NSF Design and Manufacturing Grantees Conference, Albuquerque, NM, January 3-5, 1996.

(Bausch 1995) Bausch, III, J. J., "Flexible Tooling and Fixturing" Short Course for United technologies Advanced Studies Program, October 25, 1995.

(Bausch 1996) Bausch, III, J.J,, Gold, F.M,, Moreno, V., Sisson, Jr., R. D., "Education within a Learning Factory at Pratt \& Whitney and WPI", Society of Manufacturing Engineering International Conference on Education in Manufacturing, San Diego, CA, March 13-15, 1996.

(Hoffman 1991) Hoffman, E. G., cd., Fundamentals of Tool Design, Society of Manufacturing Engineers, Dearborn, MI, 1991.

(Sisson 1994) Sisson, Jr., RD., George, A., Shyam-Sunder, S., Eager, T , Park, E., Ray, P., Durgin, W., "Manufacturing Education for Product Realization: The REALIZATION Consortium", A Proposal to the Technology Reinvestment Project 1994.

(Sisson 1996) Sisson, Jr., R. D., Acuna, N. M., "The Results of the 'Gaps Analysis in Undergraduate Engineering Education' by the Industrial Advisory Board to the REALIZATION Consortium: An Analysis”, ASEE Conference on Manufacturing Education, Washington, DC., June 1996. 